\title{
A Pioneering Tactic for Sustainable Waste Management: Design of a Cost-Effective Recycling Machine
}

\author{
A. Agarwal ${ }^{1 *}$ \\ ${ }^{1}$ Department of Mechanical Engineering, University of Botswana, Gaborone. Botswana
}

\begin{abstract}
In this paper we discussed the new design, fabrication and testing of a mechanical can crusher taking into deliberation the force analysis and ergonomic factors that will enable people to use this mechanical can crusher especially in Botswana rural areas. The process of crushing cans is of vital importance as it saves a percentage of space for can disposal and also makes it easier for these cans to be transported to recycling centers or landfill areas. The methods and processes used to bring this project to life include welding, cutting, bending, drilling and assembly operations. This project study is mainly about generating a new concept of a mechanical can crusher that is compact to transport from one location to another and makes can crushing easy and fascinating to the general public so as to promote people buy into crushing in Sub-Sahara market. Even though there are numerous sorts of the mechanical would crusher be able to as of now in presence, this model provides a more practical usage than previous one with the desired mechanical advantage of 10 , machinability to crush the entire cans to $25 \%$ of their original size and $100 \%$ efficiency for the entire rounds.
\end{abstract}

Keywords- Fabrication, cans, crusher, size reduction, mechanical advantage.

\section{Introduction}

Botswana is arguably the fastest growing economy in Africa. The Republic of Botswana is facing a lot of problems due to this rapid growth. Botswana is hard hit by an ever increasing problem of pollution. This problem is perpetuated by a number of factors including lack of garbage collection facilities (such as garbage collection trucks), poor town planning resulting in landfills being unable to keep up with the amount of garbage being piled up in them, delayed garbage collection by the city councils resulting in bins overflowing and lastly by peoples ignorance towards keeping the environment clean [1]. The majority of these cause factors can be minimized by employing the mechanical can crusher as it provides a quick fix solution to a persistent problem. Jesse M. wright developed the crusher be able to in 1937 to diminish the volume of the jars and licensed it in 1938. Capacity is regularly an issue and jars devour part of room, in this way expanding all out volume of waste [2]. Primarily the mechanical can

crusher's purpose is to reduce the size of the can so as to save space and allow for a storage of more cans and for recycling purposes. In dealing with problems of pollution it is essential to first understand the various types of pollution. There is a wide variety of pollution including water pollution, sound pollution and air pollution but to name a few. In this paper however, we shall deal with land pollution, solid waste pollution to be more specific. The problem of solid waste pollution in Botswana has reached a point where it cannot be solved within a short time frame. As a way of trying to reverse the negative environmental implications of solid waste pollution there is urgent need for all stakeholders to come up with innovative measures which will deal with the problem at grass root level [3]. Solid waste has negative effects on sectors of the economy specifically the tourism and agricultural sectors. In the tourism industry/sector solid waste robs the earth of its natural beauty making the land unattractive to tourists and as a result of this the number of tourists will decline along with the revenue they bring in. In the agricultural sector solid waste is problematic mostly to cattle farmers. Cattle can swallow solid waste such as plastics and cans and this result in beef being condemned at abettors such as the Botswana Meat Commission. A failure to meet market demands results in customers looking for new suppliers and these results in the closure of the abattoirs [3]). In Botswana at this current point in time the only can crushing platform is provided by a company called Collect-a-can which crushes cans only at an industrial (large) scale. The researchers feel that this does not solve the persistent problem of pollution as people continue to litter and garbage bins continue to pile up due to lack of solid waste management facilities such as garbage collection trucks [4]. This 
model however will solve the problem from a grass root level as it will take more time for bins to fill up. Also we believe that new technologies will provoke peoples buy in into waste separation and recycling as people will be fascinated by this new technology.

\section{Literature Review}

The can crusher is a basic idea that has already been established and tested. In this project study the focus is to improve the can crushers that are already in existence in the market. By definition Figuring out, additionally got back to building, is the procedures of removing learning or plan data from anything manmade and re-delivering it or re-creating anything in light of the extricated data. Transfer is the minimum economical and the slightest favored choice in the waste administration chain of importance. The waste administration was initially created to remove undesirable material from individuals' settlements. It was only during the recent times that the waste is moving in the upward direction towards resource recovery in many developed countries, but disposal is still the preferred final destination for most developing countries. The commonly practiced disposal methods are Landfilling and Incineration (United Nations Environment Programme, 2005).

The Collect-A-Can is a company which is involved in buying and collection of metal cans from the city as well as in the landfill. This company also has its mother plant in South Africa. The company welcomes cans from all parts of the society in Gaborone. The company has agents throughout Botswana, who is involved in buying and collection of cans. The agents buy the cans at 0.42 Pula per kilogram and sell it to the company for 1 Pula per kilogram. The collectors in the landfill are also paid based upon the amount of cans they collect. The recovered metal cans are then subjected to processing where it is crushed and pressurized in the form of a bundle which are later sent to South Africa for further processing and material recycling. The company has future plans to enhance their method and performance of collection. They plan to introduce drop off machines for the can in the city's main areas such as shopping malls and commercial areas, buy back centers in the rural part of the country, and the company has also planned to set up a plant.

\subsection{Existing can crushers}

The main aim of a can crusher is to crush used cans to reduce their size ultimately saving storage space for waste. While they are different types of can crushers with varying components to fit their design and purpose, there are certain features that are similar across all of them. These features include a crushing mechanism which allows for a can to be fed into the crusher and crushed. Following are the existing types of can crushers-

\subsubsection{Pneumatic can crusher}

Here the crushing of the cans is done by using compressed air channeled into a pneumatic cylinder with a piston coupled to a shaft and compression plate at the other end. When the air is pressurized into the cylinder the piston is pushed out and in turn pushes the compression plate that compresses the can against a stationary wall. To relief the can pressurized air is released into the atmosphere and the piston retracts [5]. It is cannot be used for heavy duty crushing.

\subsubsection{Hydraulic can crusher}

A similar working principle is followed as in pneumatic can crusher with the difference being the medium used to transfer power. In a hydraulic can crusher a cylinder is needed to but instead of air, hydraulic fluid is pressurized into the cylinder to push the compression plate that crushes the can but this time to relief the can. The hydraulic fluid is released back into the system (closed system) once the crushing action has been completed. Hydraulic fluid is not readily available, expensive and some of the transmission fluids are not environmentally friendly.

\subsubsection{Manual can crusher}

The last type of can crusher is the manual can crusher which is the most popular type of can crusher. This popularity is due to it the fact that it is cheap and simple to design. Compared to its cousins the pneumatic and hydraulic crushers the manual can crusher uses human effort as a power source instead of compressed air or compressed hydraulic fluid. To smash a can it is loaded into the crusher and human effort is needed for the crushing process. Manual can crushers can be designed to be operated by foot or hands depending on the users' preference [6]. Manual can crusher is an inexpensive type of can crusher which requires minimal maintenance during its life.

\subsubsection{Hand operated}

This kind of crusher is able to be worked by hand physically. This type of can crusher is made of either wood and metal or even plastic. Metal made can crushers are mostly used, but are relatively expensive when compared to those made from wood or plastic.

\subsubsection{Foot operated}

The crusher be able to is anything but difficult to utilize and accompanies a help bar which is intended to keep jars from being constrained out of the crusher be able to by the weight of the foot plate being pushed down. The crusher likewise includes a puncturing 
screw which can be acclimated to help pounding harder jars.

\section{Problem statement \& Scenario in Botswana}

Solid waste in general refers to all the wastes that are generated from household, commercial, industrial and agricultural sectors. The system relating to environmental protection in Botswana is still considered to be at infancy stage. Until 2002 , there was no proper record of the composition of solid waste that was generated annually in Gaborone landfill [4].The major instrument used for solid waste management in Botswana is the Waste Management Act (Laws of Botswana,2011) and Botswana's strategy for waste management (Botswana Environmental Information system,2011). The waste management act provides some regulatory measures for the waste collection disposal and recycling. The local authorities are responsible in making these regulations effective, in reality [3]. The efforts of various stakeholders such as The Botswana Government and NGO's such as Collect-A-Can and Tshomarelo Tikologo to try and sensitize people about proper solid waste disposal seem to be in vain as pollution is still a persistent concern. People continue to litter and to make matters even worse there are poor waste disposal facilities such as the inadequacy and unreliability of garbage pickup trucks resulting in waste build up. This waste unfortunately ends up over spilling and polluting the surrounding even more. At the end of the design and fabrication process the end model is expected to be able to reduce the scrape volume of the aluminum cans which are a main constituent of the solid waste. By reducing the scrape volume of the aluminum cans this will provide more storage space for solid waste in garbage bins resulting in less over spillage and less pollution into the environment. The can crusher will reduce the cans volume to increase storage space and reduce pollution. The manual can crusher will be more mechanically advantageous to help human efforts and has a hopper to temporarily store cans and act as a semi-automated feeder mechanism when the crushing operation is being carried out. Following are the base line objectives-

i. To design and fabricate a mechanical can crusher at a low cost.

ii. To plan and create a mechanical crusher be able to that has a programmed nourish container.

iii. To design and fabricate the can crusher that has storage to locate the can after crush.

iv. To improve people's buy-in into recycling, waste separation and proper solid waste management.

\section{Methodology-}

Can crusher works on the principle of slider crank mechanism. In this turning movement of hand wheel is changed over into responding movement of slider i.e. A wrench is an arm connected at right points to a turning shaft by which responding movement is granted to or gotten from the pole. It is utilized to change over round movement into responding movement, or some of the time responding movement into roundabout. The arm might be a bowed segment of the pole, or a different arm connected to it. Appended to the finish of the wrench by a rotate is a pole, normally called an interfacing pole. The finish of the bar appended to the wrench moves in a roundabout movement, while the opposite end is generally obliged to move in a straight sliding movement, in and out. The following are the proposed models from which the selection will be made. The criteria used is choose a model looks at the model that satisfy most of the project requirement these include a compact crusher, attractive to the consumer while maintaining a low cost to fabricate.

\subsection{Concept 1}

In order to achieve the best possible mechanical advantage a gear system is the best power transmission means available. The proposed model was selected for the above stated reason and also because it has an automatic feed hopper which increases the storage capacity of the entire device.

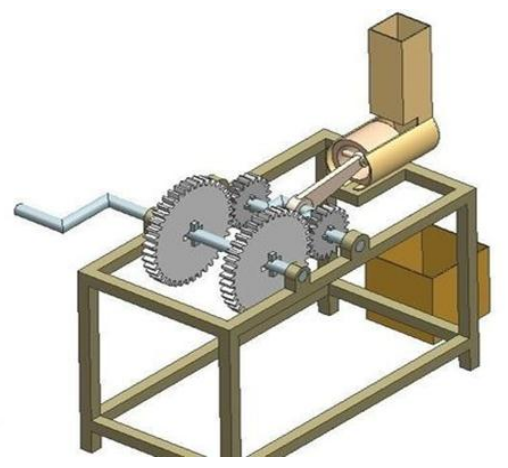

Fig. 1: The first proposed model.

The proposed model as shown in figure 1 was seen to be wasteful in the use of material. Firstly for the frame instead of using square bars for it would be wiser to use angle spacers as they are made of less material and can also offer the structural rigidness that is required from the frame. It is also clear that there are two sets of gear trains on the can crusher.

The use of the one set of a gear train is as effective as using two so it would be wiser to use only one set as the same results will be achieved will a much lower budget as also guards against material wastage. The crusher lever has the same diameter as that of the 
shaft. This is also unnecessary as to achieve mechanical advantage the crusher leaver has to have a smaller diameter as compared to the shaft diameter. In addition to this this excess material on the diameter is wasted.

\subsection{Concept 2}

The chain driven system is cheaper than a gear system and it is for that reason that we proposed this model. The chain maintenance is also cheaper and chain failure is also less as compared to the gear driven system. The second concept as shown in figure 2 was an improvement from the first concept.

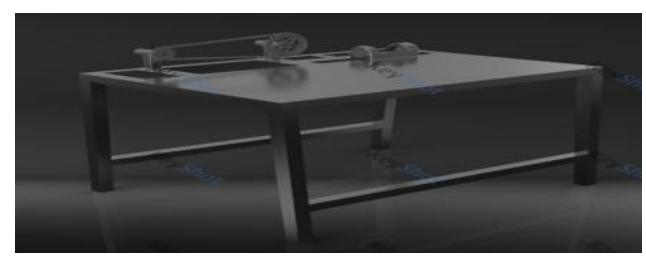

Fig. 2: The second proposed model

The input from the first sprocket (driving sprocket) to the driven sprocket insured that mechanical advantage was implemented correctly. The only problem with this concept was that the power transmission mechanism does not offer the best alternative in terms of input power by the user. A gear train mechanism is more advantageous as compared to a chain driven device so for these reasons this concept was sidelined.

\subsection{Concept 3}

The gear driven system offers the best mechanical advantage. We chose this model because it offers the best mechanical advantage at a cheaper cost as it only utilizers one set of a gear train. And also the storage capacity is maximized.

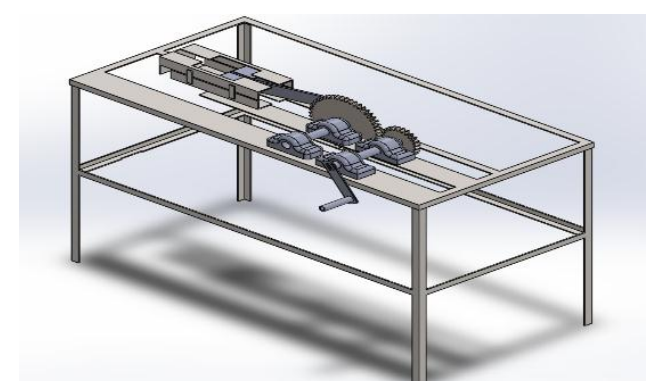

Fig. 3: Approved model of the design.

The

third concept was seen to be the best alternative as it satisfied all the objectives tasked to the project. The concept as shown in figure 3 offers maximum exploitation of the concept of mechanical advantage as the gears are arranged in the correct manner. Also, the design is user friendly, as it is in no way complex to the user to understand. It also offers other advantages which will be discussed in depth in subsequent chapters.

\section{Analysis and design consideration}

After a model concept design has been chosen a though mathematical analysis of the model is done. This will help in making the right decisions in terms of the material selection to meet the objective of the project. The mathematical analysis will touch in detail on the force that the crusher will need to crusher a standard aluminum can. After the force has been established, analysis of the components dimensions to ensure they manage the force exerted. These components include the drive shafts and gears driving the crank mechanism as shown in figure 4.

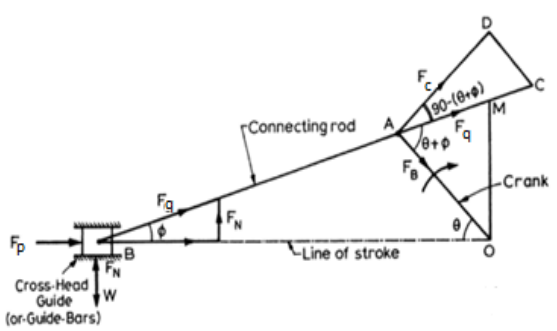

Mechanical Fig. 4: Four bar linkage mechanism

Advantage $=$

Output Force / Input Force

Specifications of Can, Can volume $=330 \mathrm{ml}$

Height $\quad=115 \mathrm{~mm}$

Diameter $=66 \mathrm{~mm}$

Thickness of aluminum can $=0.1 \mathrm{~mm}$

Yield compressive strength of $\mathrm{Al}=90 \mathrm{Mpa}$

Therefore force applied by the slider to crush the can should be $\geq 170 \mathrm{~N}$

The crushing force the product exerts on the drink-can shall be at least 170 N. Since we want our model in safe zone so we are considering a factor of safety and taking output crushing force $200 \mathrm{~N}$

Input Force applied on hand wheel $=20 \mathrm{~N}$

$\mathrm{n}=1 / \mathrm{r}=$ length of connecting $\mathrm{rod} /$ radius of $\mathrm{crank}=$ $290 \mathrm{~mm} / 75 \mathrm{~mm}=3.86 \approx 4$

Crank angle at particular instant $\theta=60^{\circ}$

$1 \sin \Phi=r \sin \theta$

$$
\begin{aligned}
\cos \Phi & =1 / \mathrm{n} \times\left(\mathrm{n}^{2}-\sin ^{2} \theta\right)^{1 / 2} \\
& =1 / 4 \times\left(4^{2}-\sin ^{2} 60\right)^{1 / 2} \\
& =0.9764 \\
\Phi & =12.5^{\circ}
\end{aligned}
$$

Force acting along connecting $\operatorname{rod} \mathrm{F}_{\mathrm{q}}$

$\mathrm{F}_{\mathrm{q}}=\mathrm{F}_{\mathrm{p}} / \cos \Phi=200 / \cos 12.5$

Crank Effort $\mathrm{T}=\mathrm{F}_{\mathrm{c}} \times \mathrm{r}$ 
$\mathrm{F}_{\mathrm{p}}=$ Axial force along sliding rod

$\mathrm{F}_{\mathrm{c}}=\mathrm{F}_{\mathrm{p}} \times \sin (\theta+\Phi) / \cos \Phi=200 \times \sin (60+$

$12.5) / \cos 12.5=195.4 \mathrm{~N}$

$\mathrm{T}=195.4 \times 0.075=\underline{14.65 \mathrm{Nm}}$

$\omega=2 \pi \mathrm{N} / 60=0.628 \mathrm{rad} . / \mathrm{sec}$

Speed ratio $=\mathrm{rpm}$ of hand wheel $/ \mathrm{rpm}$ of $\mathrm{crank}=$

$\mathrm{N}_{1} / \mathrm{N}_{2}$

Gear ratio $=4 \quad 4=\mathrm{N}_{1} / 6$

$$
\mathrm{N}_{1}=\underline{24 \mathrm{rpm}}
$$

Power Transmission from hand wheel to crank is equal $\mathrm{T}_{1}=14.65 \times 6 / 24$

$\mathrm{T}_{1}=\underline{3.66 \mathrm{Nm}}$

Calculation for hand wheel

$\mathrm{T}=\mathrm{F} \times \mathrm{r}$ If we are taking radius of hand wheel $=$

$235 \mathrm{~mm}$

Then, $3.66=\mathrm{F} \times 0.235 \mathrm{~F}=\underline{15.57 \mathrm{~N}}$

Mechanical Advantage $=$ Output Force $/$ Input Force

$=200 / 15.57=12.8 \approx 10$

Therefore this satisfies the desired mechanical advantage of 10 .

As we want to crush 6 cans in one minute, so from power transmissions equation and from balancing point of view

Gear ratio $=4$ No. of teeth in gear $=120$ and, no. of teeth in pinion $=30$

Pitch circle diameter of gear $=190 \mathrm{~mm}$

Module $=$ pitch circle dia. $/$ no. of teeth in gear $=190 /$ $120=1.58 \approx 2$

For use with highly reliable materials where loading and environmental conditions are not severe and where weight is an important consideration therefore the factor of safety is taken as 1.5

Torque $=$ Crank effort $*$ Radius of $\operatorname{crank}$ But $\mathrm{T}=\mathrm{F} *$ $\mathrm{R}$ Then, $4.96=\mathrm{F} \times 0.235$

$\mathrm{F}=21.1 \mathrm{~N}$,

Torque $=$ force $\times$ length of lever $=21.1 \times 272$

\begin{tabular}{|c|c|}
\hline CANS & LENGTH $(\mathbf{m m})$ \\
\hline 1 & 28.8 \\
\hline 2 & 27.7 \\
\hline 3 & 29.9 \\
\hline 4 & 30.1 \\
\hline 5 & 29.0 \\
\hline 6 & 27.0 \\
\hline 7 & 29.1 \\
\hline 8 & 28.8 \\
\hline 9 & 29.2 \\
\hline 10 & 30.3 \\
\hline 11 & 30.1 \\
\hline 12 & 27.4 \\
\hline
\end{tabular}

$\mathrm{T}=\mathbf{5 . 7 4 \mathrm { Nm }}$

For shafts Using Gorge Sign approachPermissible stress equation

$\sigma=\frac{s_{y t}}{n}$ $\sigma=\frac{215}{1.5}=143.33 \mathrm{MPa}$

To find the shaft diameter

$\sigma \geq \frac{M}{z} ; Z=\frac{\pi d^{3}}{32}$

The equation to find the diameter of the shaft

$d \geq \sqrt[3]{\frac{32 M}{\pi \sigma}}$

$d \geq \sqrt[3]{\frac{32(14.65)}{\pi 143.33 \times 10^{6}}}=\mathbf{0 . 0 1 3 4} \mathbf{m}$ or $13 \mathrm{~mm}$

\section{Testing and Result discussion}

Once the desired design had been achieved and the specification of the material and dimensions had been done, fabrication processes were employed to bring the product to reality. These processes include wielding, cutting measuring and marking, drilling and grinding. These processes were chosen as they were more cost effective coinciding with the objectives of the work. The model as shown in figure 6 is operated by only one person and can crush up to 360 cans an hour at full load.

A can is fed into the crushing compartment and the lever is rotated to crush the can. Once the can has been crushed in falls into the collection chamber were it will be stored whilst awaiting transportation to the recycling facilities

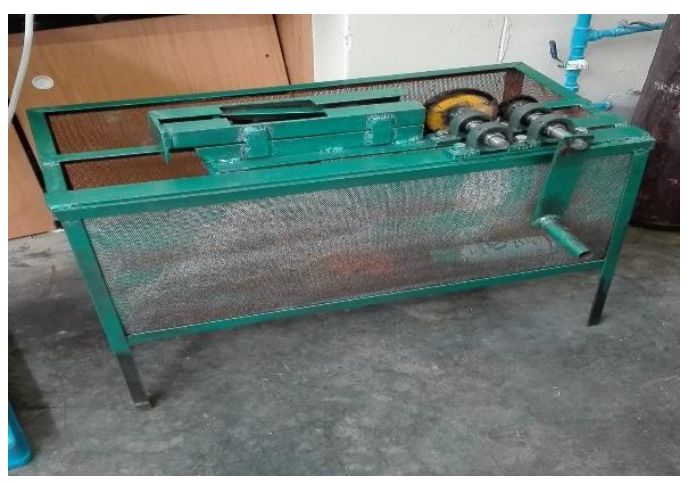

Figure 5: Finally fabricated can crusher.

The can crusher is relatively easy to use as it requires only the turning of the lever for the crushing operation to take place. The cans were started off with the one and then it was fed into the crusher by hand to be crushed. The can was measure to see if the met the desired length of $25 \%$ the original size.

Height of the can $=115 \mathrm{~mm}$.

The results of the length of the can after crushing is shown in table 1-.

Table 1: The results of the length of the can after crushing. 
Number cans crushed to desired size $=12$

Total number of cans crushed $=12$

$$
\begin{array}{r}
\text { efficiency }=\frac{\text { no. cans crushed to desired size }}{\text { total no. of cans crushed }} \\
\text { efficiency }=\frac{12}{12}=100 \% \\
\text { cycle time }=\frac{\text { processing time }}{\text { number to be processed }} \\
\text { cycle time }=\frac{60 \text { seconds }}{3 \text { cans }}=\mathbf{2 0} \text { sec. per can }
\end{array}
$$

The actual product was measured against the desired design to test if it met the required engineering standard and objective of the project. After the can crusher satisfied the design tests were ran to find if it met the required performance objectives. After testing the performance of the can crusher it was determined that the throughput of the can crusher was able to crush 3 cans per min. The Can- before and after crushing are shown in figure 6.

We managed to crush 12 cans successfully with no glitch in the operation of the crank mechanism. And we achieved to crush the entire cans to $25 \%$ of their original size, as seen in figure with $100 \%$ efficiency for the entire rounds. The model was designed to crush cans of a known capacity only (330ml).

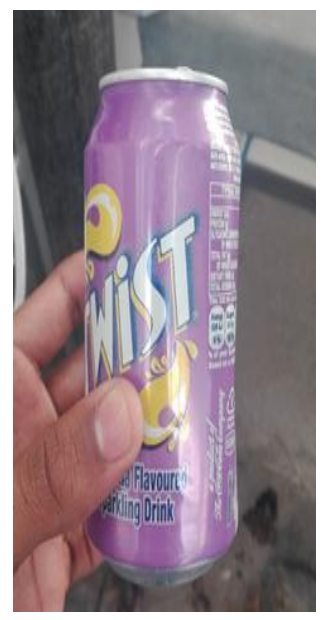

Only beverage cans are to be crushed by Fig. 6 can- before and after crushing. the model. In terms of storage capacity the design does not offer limitless storage and requires regular emptying. The can crusher can only crush one can at a time since its intended application was for small scale usage.

\section{Conclusion}

The fabricated model was successful in achieving its intended application. This model was however a foundation stone of can crushing design and fabrication in the University of Botswana and invites future scholars to improve the design were possible. The can crusher is able to crush 6 cans a minute and it can be placed in any location without diminishing its crushing capacity. The can crusher should be designed to be able to crush cans of all beverage capacities (330 $\mathrm{ml}, 440 \mathrm{ml}$ etc.). The crusher should not only be restricted to crushing beverage cans but should also crush other food stuff cans such as bean and fish cans. The crusher should also be designed in a manner that would allow it to crush multiple cans at a time so as to improve its efficiency. A motor powered by solar panels can be used to crush the cans to completely eliminate human effort.

\section{References}

1. R. P. F. T. J. Government, "scoping report for the state of waste," p. 5, March (2013).

2. kartikey desai courtney jones, sarah kasi and jon ko, "can crusher project," 4th period-tech.

3. Kgathi d.1. \& bolaane b., waste management \& research, vol. 19, pp. 342-353, (2001).

4. Ketlogetswe c. \& mothudi t.h., resources conservation and recycling, vol. 44, pp. 333342, (2005).

5. Surve qais, sayed saif, sayed jafar, shaikh nadeem, international journal of mechanical and industrial technology, pp. 155-159, 2015.

6. R. Kumar, "product innovation," (2005)

7. N. Delson, 6 october 2016. [online]. Available:

http://www.maelabs.ucsd.edu/mae_guides/m achine_design/machine_design_basics/mech $\mathrm{ad} / \mathrm{mech}$ ad.htm.

8. Properties-of-aluminium; 2016. [Online]. Available:

http:/www.aluminiumdesign.net/whyaluminium/properties-of-aluminium/.

9. George larsen nelson, in analysis of the fourbar linkage, wiley, new york, technology press of the massachusetts institute of technology, 1951, p. 730.

10. Ning gu, in computational design methods and technologies, igi global, (2012). 11.

a. Elfasakhany, j. Marquez, e.y. rezola, j. Benitez, "international journal of mechanical engineering and technology," p. 112, 2012.

12. J. J. Ward, applied mechanics, uk, macmillan education uk, 1972, pp. 48-60.

13. R. K. Bansal, "theory of machines," in theory of machines 4th ed, bangalore, india, laxmi publications, 2006, pp. 553-560.

14. "Three useful techniques in four-bar linkage design: a review," asme, 1968, p. 4.

15. P. M. F. Ashby, "materials selection $\neg$ what is materials," 4 march 2010. [online]. 
Available:

http://www.azom.com/article.aspx?articleid= 5134

16. P. M. F. Ashby, "materials selection $\neg$ what is materials," 4 march 2010. [online]. Available:

http://www.azom.com/article.aspx?articleid= 5134.

17. I. G. A. P. Francis, "office for national statistics uk material flow review," uk material flow review, january 2005.

18. R. P. F. T. J. Government, "scoping report for the state of waste-2," p. 5, march 2013.

19. C. Houska, "metal for corrosion resistance: part 2," the construction specifications institute, 99 canal center plaza, suite 300, alexandria, 2000.

20. P. Michael pfeifer, "5 materials selection steps for superior products," in materials enabled designs, 1st edition the materials engineering perspective to product design and manufacturing, 2009.

21. Handbook of mechanical engineering $2 \mathrm{nd}$, s. Chand publishing empowering minds, pp. 351-352; (2008).

22. A. Slocum, 2008. [online]. Available: http://web.mit.edu/2.75/fundamentals/fundam entals $\% 20$ book $\% 20$ pdf/fundamentals $\% 20$ topi c\%204.pdf

23. A. -. F. A. N.-f. M. Stockist, 17 may 2005. [Online].

Available: http://www.azom.com/article.aspx?articleid= 2863.

24. M. H. B. M. Zulkifli, "design of a recycle bin tin can crusher," pp. 12-15, (2008).

25. Kgosisele e. \& zhaohui 1., "an evaluation of waste management in botswana: achievements and challenges," journal of america science, 2010.

26. "waste management act from laws of botswana," 1998. [online]. Available: http://www.laws.gov.bw/volume\%2014/chap ter $\% 20 \% 2065 \% 2006 \% 20$ waste $\% 20$ managem ent.pdf. [accessed 01 05201 